\title{
Identifying Structure-Property Relationships Through DREAM.3D Representative Volume Elements and DAMASK Crystal Plasticity Simulations: An Integrated Computational Materials Engineering Approach
}

\author{
MARTIN DIEHL (1) ${ }^{1,5}$ MICHAEL GROEBER, ${ }^{2}$ CHRISTIAN HAASE, ${ }^{3,4}$ \\ DMITRI A. MOLODOV,${ }^{4}$ FRANZ ROTERS, ${ }^{1}$ and DIERK RAABE ${ }^{1}$
}

1.-Max-Planck-Institut für Eisenforschung GmbH, Max-Planck-Straße 1, 40237 Düsseldorf, Germany. 2.-Air Force Research Laboratory, 2230 Tenth Street, 45433 WPAFB, OH, USA. 3.-Institut für Eisenhüttenkunde der RWTH Aachen, RWTH Aachen, Intzestraße 1, 52072 Aachen, Germany. 4.-Institut für Metallkunde und Metallphysik, RWTH Aachen, Kopernikusstraße 14, 52074 Aachen, Germany. 5.-e-mail: m.diehl@mpie.de

Predicting, understanding, and controlling the mechanical behavior is the most important task when designing structural materials. Modern alloy systems-in which multiple deformation mechanisms, phases, and defects are introduced to overcome the inverse strength-ductility relationship-give raise to multiple possibilities for modifying the deformation behavior, rendering traditional, exclusively experimentally-based alloy development workflows inappropriate. For fast and efficient alloy design, it is therefore desirable to predict the mechanical performance of candidate alloys by simulation studies to replace time- and resource-consuming mechanical tests. Simulation tools suitable for this task need to correctly predict the mechanical behavior in dependence of alloy composition, microstructure, texture, phase fractions, and processing history. Here, an integrated computational materials engineering approach based on the open source software packages DREAM.3D and DAMASK (Düsseldorf Advanced Materials Simulation Kit) that enables such virtual material development is presented. More specific, our approach consists of the following three steps: (1) acquire statistical quantities that describe a microstructure, (2) build a representative volume element based on these quantities employing DREAM.3D, and (3) evaluate the representative volume using a predictive crystal plasticity material model provided by DAMASK. Exemplarily, these steps are here conducted for a high-manganese steel.

\section{INTRODUCTION}

Controlling the mechanical behavior is the key task when developing materials for structural applications. Replacing mechanical tests by simulation studies to evaluate the mechanical performance of candidate alloys is highly desirable as it enables a significant reduction of resource allocation in the alloy design process. However, in order to get reliable results, the simulation tool needs to correctly predict the mechanical behavior in dependence of alloy composition, microstructure, and texture.
In this study, an integrated computational materials engineering (ICME) approach that enables such virtual material development is presented. It is based on the DREAM.3D ${ }^{1}$ and DAMASK ${ }^{2}$ (Düsseldorf Advanced Materials Simulation Kit) software packages and consists of the following three steps:

1. Acquire statistical quantities that describe a microstructure.

2. Build a representative volume element (RVE) based on these quantities using DREAM.3D. 
3. Evaluate the RVE using a predictive crystal plasticity material model implemented in the DAMASK framework.

Exemplarily, these steps are here conducted for a high-manganese steel (HMnS). ${ }^{3,4}$ Like other modern high-performance alloys, HMnS combine multiple deformation mechanisms to overcome the inverse strength-ductility relationship. ${ }^{5,6}$ Besides dislocation glide, both, transformation-induced plasticity (TRIP) and twinning-induced plasticity (TWIP), serve as additional deformation mechanisms. ${ }^{7,8}$ From an engineering point of view, additional deformation mechanisms create the challenge that they are influenced by several microstructural and environmental parameters such as grain size, texture, chemical composition, temperature, strain rate, and the nonlinear interactions between them. These complex interactions and influencing factors can significantly hamper accelerated alloy design, particularly when using the material under complex loading and strain path conditions such as commonly encountered in engineering sheet-forming applications. Hence, for complex engineering materials, it is indispensable to evaluate the performance of potential microstructures by fast and reliable simulations before conducting mechanical tests and even before synthesizing prototype alloys. With such simulation studies, a suitable regime in the huge parameter space can be located beforehand in order to conduct classical alloy prototyping and mechanical tests only for target-oriented validation of the computed domain.

In the proof-of-concept study presented here, statistical microstructural quantities are retrieved from an existing and experimentally well-characterized material. This allows for a comparison of calculated results with experimental data to evaluate the capabilities of the approach. However, as outlined below, using a predictive crystal plasticity model and synthetic microstructure generation raises the opportunity to use the procedure to also investigate new materials with the aim of forecasting suitable microstructures for different loading states.

The study is organized as follows. First, to give the reader a background of the investigated model alloy, a concise synopsis on HMnS is provided. Next, we explain how the microstructure features obtained from the experimental characterization are translated into appropriate statistical quantities. Then, it is discussed how these microstructure measures are subsequently used for the generation of representative microstructures using DREAM.3D. After that, we explain the simulation details of the crystal plasticity model implemented into the DAMASK software package. Finally, after presentation of the simulation results, we draw conclusions and provide an outlook on how to further improve and apply the methodology.

\section{MODEL MATERIAL}

The concept of HMnS is based on stabilizing the face-centered cubic (fcc) austenite phase. This is usually accomplished by adding a high amount of manganese (15-30 wt.\%). Small proportions of carbon (0.05-1.00 wt.\%), aluminium (0.0-3.0 wt.\%) and/or silicon (0.0-3.0 wt.\%) can be added for tuning the stacking fault energy and the oxidation layers. ${ }^{9}$ HMnS are considered to be part of the second generation of advanced high-strength steels (AHSS). The active deformation mechanism(s) in HMnS mainly depend(s) on the stacking fault energy (SFE), which is normally below $20 \mathrm{~mJ} \mathrm{~m}^{-2}$ for TRIP steels and in the range between $20 \mathrm{~mJ} \mathrm{~m}^{-2}$ and $40 \mathrm{~mJ} \mathrm{~m}^{-2}$ for TWIP steels. In HMnS with SFE values above $45 \mathrm{~mJ} \mathrm{~m}^{-2}$, dislocation glide dominates plastic deformation, whereas TRIP and TWIP effects are suppressed. ${ }^{10,11}$ The selected TWIP steel has a composition of $22.5 \mathrm{Mn}-1.2 \mathrm{Al}-0.3 \mathrm{C}$ wt.\%. Its SFE was determined by a subregular solution thermodynamic model ${ }^{12}$ as approximately $25 \mathrm{~mJ} \mathrm{~m}^{-2}$. Hence, deformation twinning is expected to be the only active deformation mechanism besides dislocation glide. Since the material has been extensively investigated in previous works, ${ }^{13-18}$ details on the production and postprocessing procedure ${ }^{15,19}$ are not repeated here.

\section{INTEGRATED COMPUTATIONAL MATERIALS ENGINEERING PROCEDURE}

\section{Experimental Characterization}

From the initial material in hot-rolled condition, six different microstructural states have been produced by imposing different (thermo-) mechanical treatments. First, the material was cold-rolled to $30 \%, 40 \%$, and 50\% thickness reduction. From these three states, recrystallized samples have been produced by subsequent annealing at $700^{\circ}$ for $15 \mathrm{~min}$ after $30 \%$ reduction and for $10 \mathrm{~min}$ after $40 \%$ and $50 \%$ reductions.

Details on sample preparation for the following electron backscatter diffraction (EBSD) and x-ray diffraction analyses used for the material characterization can be found in an already published study. ${ }^{15}$

A LEO 1530 field emission gun scanning electron microscope operated at $20 \mathrm{kV}$ accelerating voltage and a working distance of $10 \mathrm{~mm}$ was used for EBSD analyses. EBSD mappings were generated with a step size of $0.28 \mu \mathrm{m}$. The HKL Channel 5 software was utilized for data post-processing and the removal of wild spikes and non-indexed points, taking at least five neighbor points into account. Based on EBSD measurements, grain size distributions of the cold-rolled and subsequently recrystallized state were retrieved. In contrast, the shape and the mean grain size of the cold-rolled samples were estimated from measurements on the material in the hot-rolled state. EBSD band contrast maps of 
the $40 \%$ cold-rolled samples before and after recrystallization are shown exemplarily in Fig. 1. The typical grain morphology of cold-rolled material, i.e. grains elongated along the rolling direction (RD) and compressed along the normal direction (ND), is shown in Fig. 1a. The smaller, equiaxed grains of the recrystallized sample are displayed in Fig. $1 \mathrm{~b}$.

The crystallographic texture was characterized by means of x-ray pole figure measurements. Three incomplete $\left(0^{\circ}\right.$ to $\left.85^{\circ}\right)$ pole figures- $\{111\},\{200\}$, and $\{220\}$-were acquired at the mid-thickness layer of the sheet on a Bruker D8 Advance diffractometer, equipped with a HI-STAR area detector, operating at $30 \mathrm{kV}$ and $25 \mathrm{~mA}$ using filtered iron radiation and polycapillary focusing optics. The orientation distribution functions (ODFs) were calculated in the MATLAB-based MTEX package. ${ }^{20,21}$ $\varphi_{2}=45^{\circ}$ sections of the ODF of the six investigated states are shown in Fig. 2. The corresponding legend of the ideal texture components is given elsewhere. ${ }^{22}$ With increasing rolling degree, the texture transformed gradually from Cu-type to Brass-type, as indicated by the decreasing $\{112\}\langle 111\rangle \mathrm{Cu}$ texture component and the more

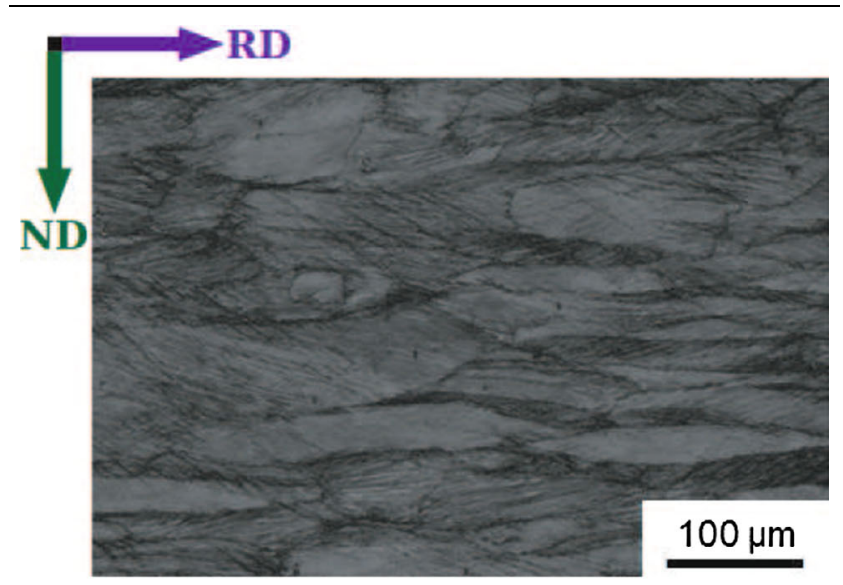

(a)

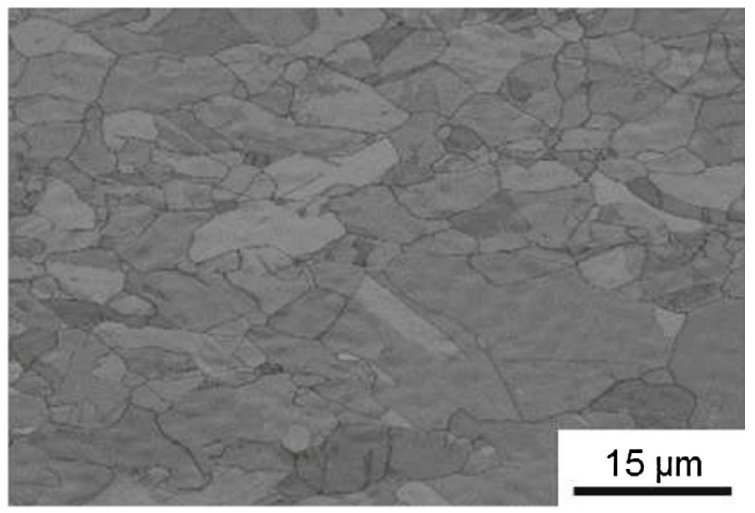

(b)

Fig. 1. EBSD band contrast maps of the high-manganese steel material. (a) After $40 \%$ thickness reduction by cold rolling. (b) After $40 \%$ thickness reduction by cold rolling and subsequent recrystallization at $700^{\circ}$ for $15 \mathrm{~min}$. pronounced $\alpha$-fiber $(\langle 110\rangle \| \mathrm{ND})$ with a spread towards the $\{552\}\langle 115\rangle$ CuT texture component. After recrystallization, the rolling texture was retained but significantly weakened in intensity as a result of the oriented nucleation and the formation of recrystallization twins. ${ }^{23,24}$

The obtained grain size distribution data as well as the orientation information obtained from the experimental ODFs are then used as input to generate the RVEs as outlined in the following.

\section{Representative Volume Element Generation Using DREAM.3D}

The DREAM.3D software ${ }^{1}$ was used to generate the RVEs using statistics extracted from the experimental data following a procedure outlined elsewhere. ${ }^{25,26}$ DREAM.3D has been extensively used to

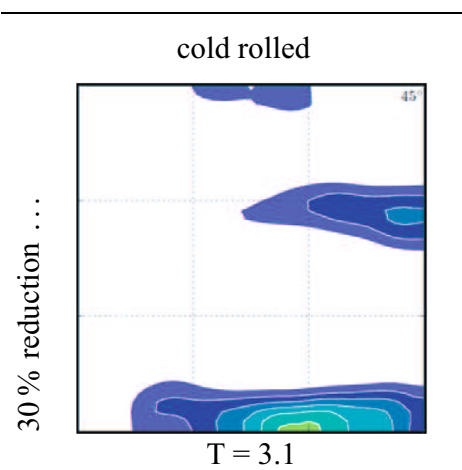

$\ldots$ and recrystallized
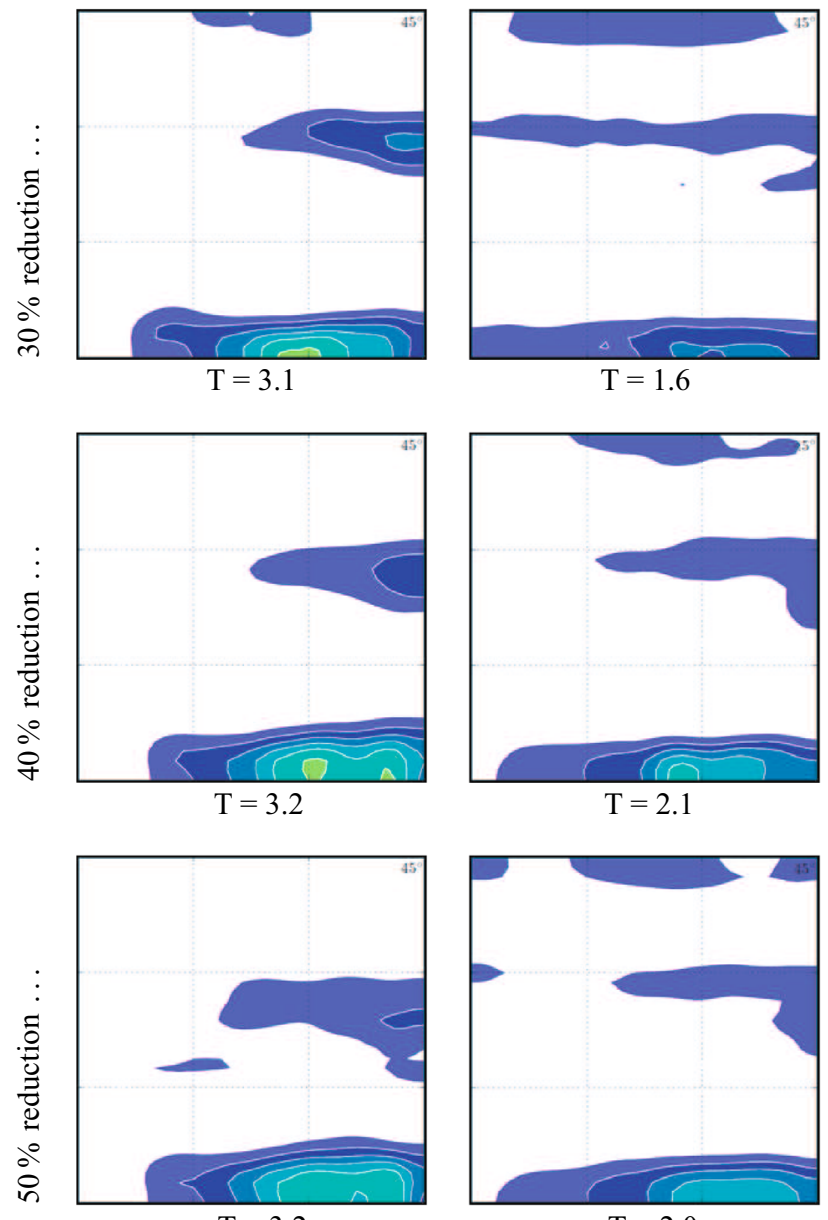

$\mathrm{T}=3.2$

$\mathrm{T}=2.0$

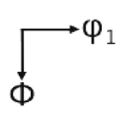

0.0

12.0

Fig. 2. $\varphi_{2}=45^{\circ}$ sections of the orientation distribution function of the six material states. The color code indicates orientation density $\mathrm{f}(\mathrm{g}) ; T$ is the texture index. 
characterize experimentally acquired microstructures and generate microstructure-based models for subsequent simulations. ${ }^{27-32}$ Since it produces $3 \mathrm{D}$ virtual volumes, the experimentally obtained data were extrapolated from $2 \mathrm{D}$ to $3 \mathrm{D}$ based on some underlying assumptions. First, the diameter of the sphere-shaped grains in the original (hot-rolled) state was determined experimentally. These spheres were then assumed to deform isomorphically during $30 \%, 40 \%$, and $50 \%$ thickness reduction to yield the grain morphology of the solely coldrolled states. In contrast, the grains in the coldrolled and subsequently recrystallized states were assumed to be nearly equiaxed, i.e. the measured diameters $(d)$ along $\mathrm{RD}, \mathrm{ND}$, and transverse direction (TD) are similar $\left(0.8<d_{N D} / d_{R D}<d_{T D} /\right.$ $\left.d_{R D}<1.0\right)$. The average grain diameters for each state were then determined by calculating the mean lineal intercept in 2D and extrapolating to $3 \mathrm{D}$ by the relationship $d_{3 D}=1.5 d_{2 D}$. The crystallographic texture in each state was used directly from the calculated ODFs. The microstructure was simplified in such a way that a single orientation was assigned to each grain and no internal orientation gradients exist for either cold-rolled nor cold-rolled and recrystallized states. It is important to note that the constructed volume elements are microstructurally representative, and multiple instantiations will produce volumes with similar microstructural characteristics. However, the volumes can be termed properly representative only if multiple instantiations yield similar simulated properties (Fig. 3; Table I).

\section{Crystal Plasticity Simulation Using DAMASK}

We used a dislocation-based crystal plasticity constitutive model from the DAMASK package suitable for capturing the mechanical characteristics of the investigated material class. ${ }^{8}$ This constitutive formulations introduced in DAMASK for the prediction of the mechanical response of TWIP and TRIP steels is capable of reproducing the active deformation modes depending on the SFE of the material. It is important to realize that the SFE can be directly computed from ab initio simulations. Hence, a bridge from the atomistic scale to the component scale can be established, and the model is predictive with respect to the chemical composition. As can be seen from Tables II and III, almost all other parameters of the crystal plasticity model also have a clear physical meaning, physics-related upper and lower bounds, and can be determined from small-scale simulations or microstructure characteristics.

The same material parameters as used in a previous study ${ }^{15}$ have been applied with the exception of the grain size $d$ and initial values for the edge dislocation density $\rho_{e}$, the dipole dislocation density $\rho_{d}$, and the twinned volume fraction $f_{t}$.

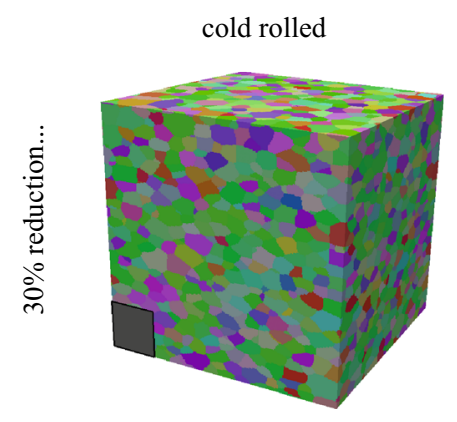

$\ldots$ and recrystallized
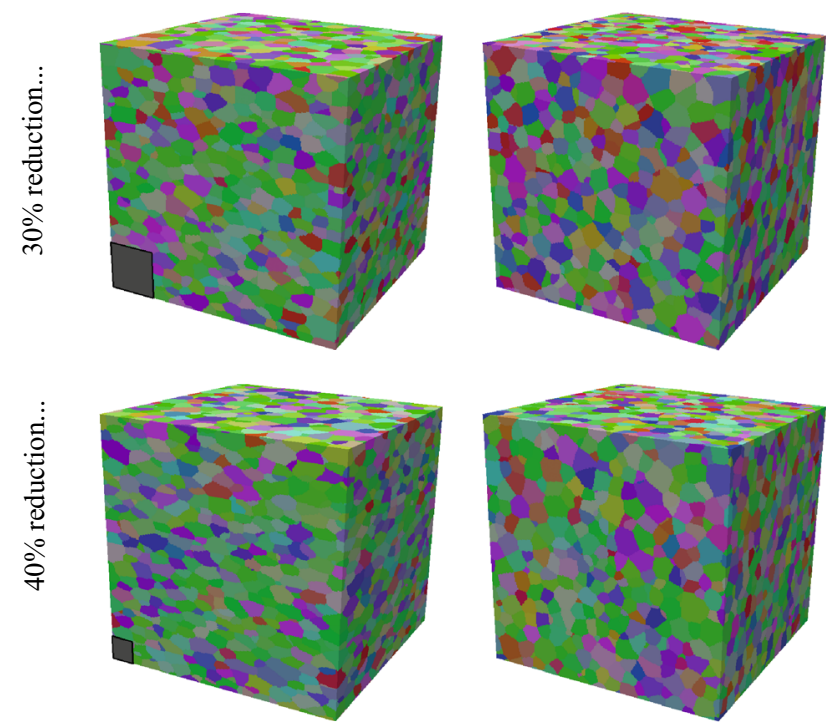

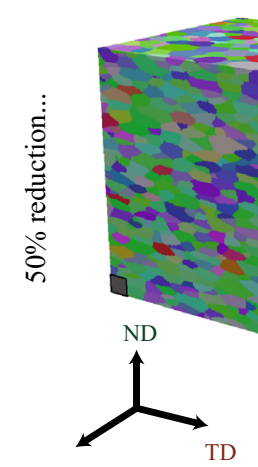

$\mathrm{RD}$

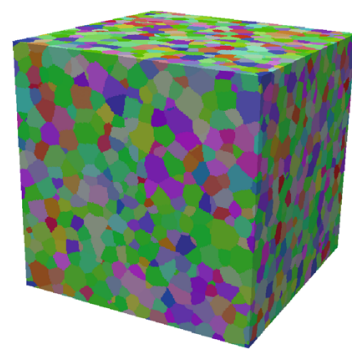

Fig. 3. Representative volume elements for the six different states colored according to the inverse pole figure along ND. Cold-rolled and recrystallized states are scaled to the same size $(640 \mu \mathrm{m}$ along each direction) as the cold-rolled state (see gray square in the lower left corner of the corresponding cold-rolled state).

Table I. Grain morphology properties of the generated representative volume elements

\begin{tabular}{|c|c|c|c|}
\hline State & Size $/ \mu \mathbf{m}^{3}$ & Grain count & Shape \\
\hline $30 \% \mathrm{CR}$ & 640.0 & 4086 & Ellip \\
\hline $30 \% \mathrm{CR}+\mathrm{RX}$ & 128.0 & 3959 & Spherical \\
\hline $40 \% \mathrm{CR}$ & 640.0 & 4041 & Ellipsoidal \\
\hline $40 \% \mathrm{CR}+\mathrm{RX}$ & 64.0 & 4585 & Spherical \\
\hline $50 \% \mathrm{CR}$ & 640.0 & 4044 & Ellipsoidal \\
\hline $50 \% \mathrm{CR}+\mathrm{RX}$ & 51.2 & 4664 & Spherical \\
\hline
\end{tabular}

$C R$ cold-rolled, $R X$ recrystallized.

For the cold-rolled and recrystallized samples, the average grain size diameter is determined from the RVE characteristics given in Table I: first, the average grain volume is computed as the RVE size divided by number of grains, followed by the calculation of the diameter of a sphere with this volume. 
Table II. Values of the parameters and their symbols used in the crystal plasticity model $^{8}$ for all simulations (a) Elasticity

$C_{11}=175 \mathrm{GPa} \quad C_{12}=115 \mathrm{GPa} \quad C_{44}=135 \mathrm{GPa}$

\section{(b) Dislocation glide ${ }^{\text {a }}$}

\begin{tabular}{|c|c|c|c|}
\hline Parameter & Symbol & Value & Unit \\
\hline Burgers vector magnitude & $b_{\mathrm{s}}$ & $2.56 \times 10^{-10}$ & $\mathrm{~m}$ \\
\hline Activation energy slip & $Q_{\mathrm{s}}$ & $1.5 \times 10^{-19}$ & $\mathrm{~J}$ \\
\hline Activation energy climb & $Q_{\mathrm{c}}$ & $2.0 \times 10^{-19}$ & $\mathrm{~J}$ \\
\hline Activation volume climb & $V_{\mathrm{c}}$ & $1.7 \times 10^{-29}$ & $\mathrm{~m}^{3}$ \\
\hline Obstacle profile top & $p$ & 1.0 & \\
\hline Obstacle profile bottom & $q$ & 1.0 & \\
\hline \multicolumn{4}{|c|}{ Mean free path in multiples of ... } \\
\hline ...dislocation spacing & $i_{\mathrm{s}}$ & 45.0 & \\
\hline ...twin spacing & $i_{\mathrm{t}}$ & 1.0 & \\
\hline Self-diffusion prefactor & $D_{0}$ & $4.0 \times 10^{-5}$ & $\mathrm{~m}^{2} \mathrm{~s}^{1}$ \\
\hline Minimum dipole spacing & $C_{\text {anni }}$ & $8.96 \times 10^{-08}$ & $\mathrm{~m}$ \\
\hline Velocity prefactor & $v_{0}$ & $1.0 \times 10^{4}$ & $\mathrm{~ms}^{-1}$ \\
\hline Solution strengthening & $\tau_{\text {sol }}$ & $2.0 \times 10^{7}$ & $\mathrm{~Pa}$ \\
\hline
\end{tabular}

\section{(c) Twinning}

\begin{tabular}{lccc}
\hline Burgers vector & $b_{\mathrm{t}}$ & $1.47 \times 10^{-10}$ & $\mathrm{~m}$ \\
Nucleus width & $L_{\mathrm{t}}$ & $2.56 \times 10^{-7}$ & $\mathrm{~m}$ \\
Avg. twin thickness & $t_{\mathrm{t}}$ & $5.0 \times 10^{-8}$ & $\mathrm{~m}$ \\
Activation volume cross-slip & $V_{\mathrm{cs}}$ & $5.0 \times 10^{-32}$ & $\mathrm{~m}^{3}$ \\
Profile width exponent & $A$ & 13.96 & \\
SFE & $\Gamma_{\mathrm{SF}}$ & 25.0 & $\mathrm{mJm}^{-2}$
\end{tabular}

${ }^{a}$ Interaction coefficients for hardening are obtained by discrete dislocation dynamics simulations. ${ }^{33}$

For the cold-rolled states, ellipsoidal grain shapes are assumed which result from the rolling of the initially spherical grains with diameter $d=27 \mu \mathrm{m}$. The shortest axis of the ellipsoid (along ND) $d_{N D}=27 \mu \mathrm{m} \times 3 / 2 \times \varepsilon \quad$ with $\quad \varepsilon \in\{0.3,0.4,0.5\} \quad$ is taken as the limiting size that determines the mean free path for dislocation glide.

The initial values of $\rho_{e}^{0}, \rho_{d}^{0}$, and $f_{t}^{0}$ are derived from the results of a plane strain compression simulation ${ }^{15}$ by calculating the average over all 12 slip and 12 twin systems at the respective deformation level, i.e. neglecting any partitioning to specific systems.

Simulations are performed using a spectral method $^{34}$ coupled with DAMASK. ${ }^{2,35,36}$ The RVEs are subjected to uniaxial tension at a loading rate of $1 \times 10^{-3} \mathrm{~s}^{-1}$. The microstructures representing the cold-rolled states are loaded along all three directions (RD, ND, TD) to investigate the anisotropy introduced by the preceding deformation. As no such anisotropy is expected for their recrystallized counterparts, owing to the weak crystallographic textures $^{37}$ and the absence of grain shape effects, those are loaded only along RD. The final strain levels have been adjusted to the experimentally obtained values for the cold-rolled states and are set to a true strain of $\varepsilon=0.16$ for simulation in coldrolled and recrystallized conditions.

\section{SIMULATION RESULTS OBTAINED BY DAMASK}

Stress-strain curves of the tensile tests conducted along RD are shown in Fig. 4 for all investigated material states. The significant hardening introduced by the cold rolling is clearly captured by the model, with the yield point of the sample with $50 \%$ thickness reduction being more than $1.0 \mathrm{GPa}$ higher than for the states with preceding recrystallization heat treatment. Moreover, the effect of the different grain sizes among the cold-rolled and recrystallized conditions can also be seen, i.e. the $30 \%$ cold-rolled and recrystallized sample hardens less than the $50 \%$ cold-rolled and recrystallized sample. Comparing these results with the experimental results (lines marked by dots) ${ }^{15 *}$, a good qualitative agreement in the elastic-plastic deformation regimes, i.e. before damage is expected to set in, can be observed. Also, the evolution of the twin volume fraction $f_{t}$

*Figure 11. 
Table III. Values of the parameters (grain size: $d$; edge dislocation density $\rho_{e}^{\mathbf{0}}$; dipole dislocation density $\rho_{d}^{0}$; twinned volume fraction $f_{t}^{0}$ ) used in the crystal plasticity model $^{8}$ adjusted for specific material states

\begin{tabular}{|c|c|c|c|c|}
\hline State & $\mathbf{d} / \mu \mathbf{m}$ & $\rho_{\boldsymbol{e}}^{\mathbf{0}} / \mathbf{m}^{-\mathbf{2}}$ & $\rho_{d}^{\mathbf{0}} / \mathbf{m}^{-\mathbf{2}}$ & $f_{t}^{0}$ \\
\hline $30 \% \mathrm{CR}$ & 28.35 & $4.5 \times 10^{13}$ & $8.1 \times 10^{13}$ & 0.0033 \\
\hline $30 \% \mathrm{CR}+\mathrm{RX}$ & 10.04 & $1.0 \times 10^{12}$ & 1.0 & 0.0 \\
\hline $40 \% \mathrm{CR}$ & 24.29 & $7.0 \times 10^{13}$ & $1.4 \times 10^{14}$ & 0.0039 \\
\hline $40 \% \mathrm{CR}+\mathrm{RX}$ & 4.78 & $1.0 \times 10^{12}$ & 1.0 & 0.0 \\
\hline $50 \% \mathrm{CR}$ & 20.25 & $9.2 \times 10^{13}$ & $1.7 \times 10^{14}$ & 0.0041 \\
\hline $50 \% \mathrm{CR}+\mathrm{RX}$ & 3.80 & $1.0 \times 10^{12}$ & 1.0 & 0.0 \\
\hline
\end{tabular}

$C R$ cold-rolled, $R X$ recrystallized.

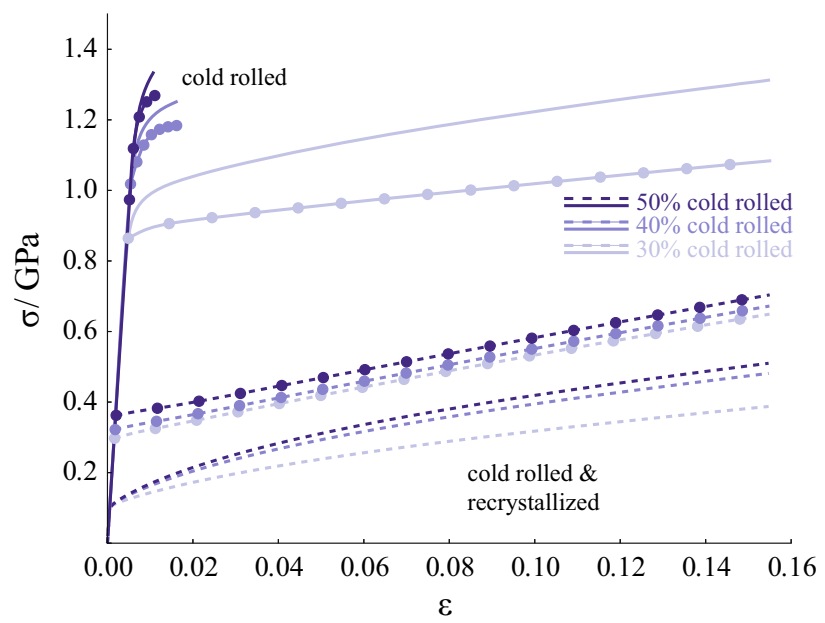

Fig. 4. Stress-strain curves for loading along RD. Broken lines indicate cold-rolled and subsequently recrystallized states, solid lines indicate solely cold-rolled states. Level of preceding thickness reduction is indicated by the intensity from bright (30\%) to dark $(50 \%)$. Experimental results are marked by additional dots.

(not shown here) follows the experimental observations: essentially, there is no twinning activity at the simulated deformation levels ${ }^{15 * *}$. The yield stress values for the cold-rolled and recrystallized state are, however, lower by approximately 180 $\mathrm{MPa}$ and the hardening rate is underestimated.

When analyzing the stress-strain curves predicted for tensile tests along the three different loading directions given in Fig. 5, it can be seen that a significant anisotropy is introduced in the coldrolled state. This behavior is especially pronounced for 50\% thickness reduction. Except for the the 30\% cold-rolled and recrystallized state, where only small anisotropy is observed, loading along RD gives the softest response.

Given the good qualitative agreement between the experimentally observed and simulated average responses, the simulation results can be used to

\footnotetext{
**Figure 13
}

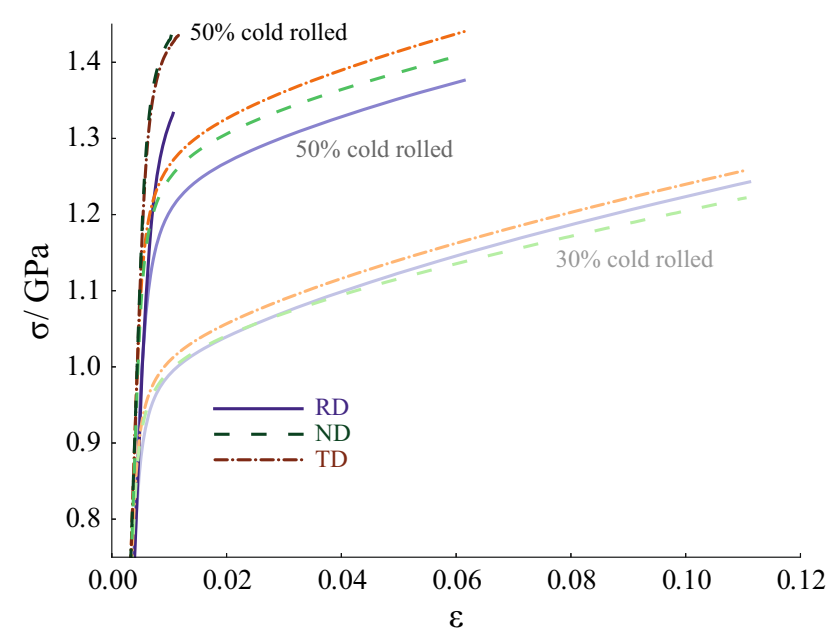

Fig. 5. Stress-strain curves (plastic regime) for loading along RD (solid lines), TD (broken lines), and ND (dashed lines). Level of preceding thickness reduction is indicated by the intensity from bright $(30 \%)$ to dark $(50 \%)$.

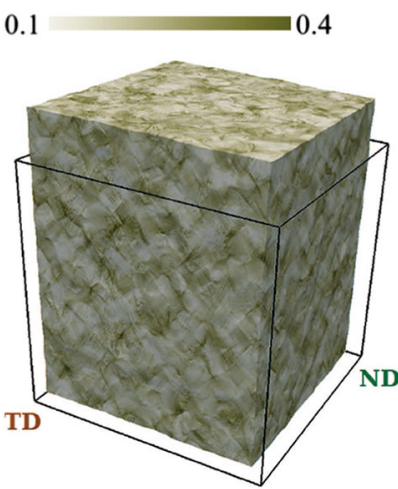

(a)

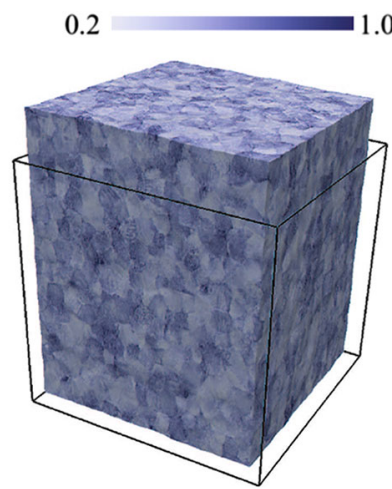

(b)
Fig. 6. Local quantities mapped onto the deformed configuration of the $30 \%$ cold-rolled and recrystallized representative volume element at $\varepsilon=0.16$ along RD. The cubic box shows the shape of the representative volume element in undeformed configuration. (a) Eq. strain $\varepsilon_{V M}$. (b) Eq. stress $\sigma_{V M}$.

study the spatial stress and strain distributions. With typical experimental equipment, these quantities cannot be readily determined at all (in the case of stress), or the acquisition requires significant efforts (in the case of strain, where, e.g., digital image correlation techniques are needed ${ }^{38-40}$ ). The local distributions of equivalent true strain $\left(\varepsilon_{v M}\right)$ and stress $\left(\sigma_{v M}\right)$ at the final loading state, i.e. at $\varepsilon=0.16$ for the $30 \%$ cold-rolled and recrystallized sample are shown in Fig. 6. We observe a significant and broad range in the distribution of stress and strain-not only among different grains but also within individual grains. Even though a quantitative agreement to the experimental stress-strain response cannot be achieved without tedious model parameter fitting, the quantitative analysis of the stress and strain distribution gives helpful insights for the development of improved alloys. 


\section{CONCLUSION AND OUTLOOK}

The presented ICME approach can assist, accelerate, and guide the design of new alloys and suitable processing pathways. Based on statistical descriptions of microstructures, RVEs are created on the basis of which the material's performance is evaluated. The use of DREAM.3D enables microstructure RVE generation at high fidelity, incorporating statistical features which can be evaluated using the spectral solver and physicalbased crystal plasticity laws for specific materials $^{8,41,42}$ available in DAMASK. Such a strictly microstructure-oriented ICME approach enables the drastic reduction in the number of experiments typically required in alloy, microstructure, and process development.

To further strengthen the link between measured microstructural features and generated RVEs, additional statistical quantities can be taken into account. Features that might have an influence on the mechanical behavior could be the in-grain orientation distribution (especially for the coldrolled states), the grain-to-grain misorientation in the form of a misorientation distribution function, ${ }^{43}$ and the exact grain shape. While incorporating rules to construct microstructures based on these additional pieces of information is a challenging task by itself, for a comparison with experimental results, data acquisition efforts will also increase. For both crystallographic features, the experimental characterization would need to be expanded to obtain not only global orientation information but also spatially resolved and neighborhood-sensitive quantities ${ }^{\dagger}$. Similarly, measurement complexity for a more exact grain shape determination requires statistically relevant 3D information, e.g., from EBSD measurements conducted on mutually orthogonal surfaces.

The employed crystal plasticity model has revealed its predictive capabilities for different chemical compositions and various temperatures. ${ }^{8}$ Most of the parameters used in this model have a physical meaning and can be obtained from smallscale simulations. However, two weak points in the model can be identified that are deemed to impede a quantitative agreement with experimental results. First, the grain size is only considered as a fixed average value to limit the mean free path for dislocation slip and does not affect the local hardening based on dislocation density gradients. Out of the various approaches of taking gradients into account, the physically most sound approaches are based on the flux of dislocations. ${ }^{42,44}$ While, on the one hand, the associated computational costs prohibit the use of such constitutive models for largescale simulations as presented here, on the other hand the effect on macroscopic properties is

†'Still, the dataset must be large enough to be representative of the material. probably not that pronounced. ${ }^{45}$ Secondly, solid solution strengthening is also not implemented in a physics-based way and its temperature dependence is neglected in the current approach. ${ }^{8}$

Another area of current research where progress will increase the quality of the results is the coupling of damage and crystal plasticity models. As damage is the dominating mechanism for the highly cold-rolled states, their behavior cannot be captured correctly within the current simulation framework. Nevertheless, current approaches of implementing damage models into DAMASK ${ }^{46,47}$ will allow the tackling of this challenge in the near future.

\section{ACKNOWLEDGEMENTS}

Open access funding provided by Max Planck Society. MD acknowledges the funding of the TCMPrecipSteel project in the framework of the SPP 1713 Strong coupling of thermo-chemical and thermo-mechanical states in applied materials by the Deutsche Forschungsgemeinschaft (DFG). CH, DAM, FR, and DR acknowledge gratefully the financial support of the DFG within the SFB 761 Steel - ab initio: Quantum mechanics guided design of new Fe based materials.

\section{OPEN ACCESS}

This article is distributed under the terms of the Creative Commons Attribution 4.0 International License (http://creativecommons.org/licenses/by/4.0/), which permits unrestricted use, distribution, and reproduction in any medium, provided you give appropriate credit to the original author(s) and the source, provide a link to the Creative Commons license, and indicate if changes were made.

\section{REFERENCES}

1. M.A. Groeber and M.A. Jackson, Integ. Mater. Manuf. Innov. 3, 5 (2014).

2. F. Roters, P. Eisenlohr, C. Kords, D.D. Tjahjanto, M. Diehl, and D. Raabe, Procedia IUTAM: IUTAM Symposium on Linking Scales in Computation, vol. 3, ed. O. Cazacu (Amsterdam: Elsevier, 2012), pp. 3-10.

3. O. Grässel, L. Krüger, G. Frommeyer, and L.W. Meyer, Int. J. Plast. 16, 1391 (2000).

4. G. Frommeyer, U. Brüx, and P. Neumann, ISIJ Int. 43, 438 (2003).

5. D. Raabe, H. Springer, I. Gutierrez-Urrutia, F. Roters, M. Bausch, J-B Seol, M. Koyama, P-P Choi, and K. Tsuzaki, JOM 66, 1845 (2014).

6. D. Raabe, F. Roters, J. Neugebauer, I. Gutierrez-Urrutia, T. Hickel, W. Bleck, J.M. Schneider, J.E. Wittig, and J. Mayer, MRS Bull. 41, 320 (2016).

7. D.R. Steinmetz, T. Jäpel, B. Wietbrock, P. Eisenlohr, I. Gutierrez-Urrutia, A. Saeed-Akbari, T. Hickel, F. Roters, and D. Raabe, Acta. Mater. 61, 494 (2013).

8. S.L. Wong, M. Madivala, U. Prahl, F. Roters, and D. Raabe, Acta. Mater. 118, 140 (2016).

9. B.C. De Cooman, K.-G. Chin, and J. Kim, High Mn TWIP Steels for Automotive Applications (InTech, 2011). http:// www.intechopen.com/books/howtoreference/new-trendsand-developments-in-automotive-system-engineering/ high-mn-twip-steels-for-automotive-applications. 
10. S. Allain, J-P Chateau, O. Bouaziz, S. Migot, and N. Guelton, Mat. Sci. Eng. A, 387-389, 158 (2004).

11. K. Sato, M. Ichinose, Y. Hirotsu, and Y. Inoue, ISIJ Int. 29 , 868 (1989).

12. A. Saeed-Akbari, L. Mosecker, A. Schwedt, and W. Bleck, Metal. Mater. Trans. A 43, 1688 (2012).

13. C. Haase, L.A. Barrales-Mora, D.A. Molodov, and G. Gottstein, Metal. Mater. Trans. A 44, 4445 (2013).

14. C. Haase, L.A. Barrales-Mora, D.A. Molodov, and G. Gottstein, Adv. Mat. Res. 922, 213 (2014).

15. C. Haase, L.A. Barrales-Mora, F. Roters, D.A. Molodov, and G. Gottstein, Acta. Mater. 80, 327 (2014).

16. C. Haase, T. Ingendahl, O. Güvenç, M. Bambach, W. Bleck, D.A. Molodov, and L.A. Barrales-Mora, Mat. Sci. Eng. A 649, 74 (2016).

17. C. Haase, O. Kremer, W. Hu, T. Ingendahl, R. Lapovok, and D.A. Molodov, Acta. Mater. 107, 239 (2016)

18. P. Kusakin, A. Belyakov, C. Haase, R. Kaibyshev, and D.A. Molodov, Mat. Sci. Eng. A 617, 52 (2014).

19. B. Wietbrock, M. Bambach, S. Seuren, and G. Hirt, Mater. Sci. Forum 638-642, 3134 (2010).

20. R. Hielscher and H. Schaeben, J. Appl. Crystallogr. 41, 1024 (2008).

21. F. Bachmann, R. Hielscher, and H. Schaeben, Sol. St Phen. 160, 63 (2010).

22. C. Haase, S.G. Chowdhury, L.A. Barrales-Mora, D.A. Molodov, and G. Gottstein, Metal. Mater. Trans. A 44, 911 (2013).

23. C. Haase, L.A. Barrales Mora, D.A. Molodov, and G. Gottstein, Mater Sci Forum 753, 213 (2013).

24. C. Haase, M. Kühbach, L.A. Barrales-Mora, S.L. Wong, F. Roters, D.A. Molodov, and G. Gottstein, Acta Mater 100, 155 (2015).

25. M. Groeber, S. Ghosh, M.D. Uchic, and D.M. Dimiduk, Acta Mater, 56, 1257 (2008).

26. M. Groeber, S. Ghosh, M.D. Uchic, and D.M. Dimiduk, Acto Mater 56, 1274 (2008).

27. A. Cerrone, J.C. Tucker, C. Stein, A.D. Rollett, and A.R. Ingraffea, Joint Conference of the Engineering Mechanics Institute and the 11th ASCE Joint Specialty Conference on Probabilistic Mechanics and Structural Reliability (Montreal, Canada, 2012).
28. A. Cerrone, A. Spear, J.C. Tucker, C. Stein, A.D. Rollett, and A.R. Ingraffea, MS\&T 2013: Materials Science \& Technology 2013 Conference (Notre Dame, IN, 2013).

29. M. Knezevic, B. Drach, M. Ardeljan, and I.J. Beyerlein, Comput. Method Appl. M 277, 259 (2014).

30. S. Ghosh, S. Keshavarz, and G. Weber, Computational Multiscale Modeling of Nickel-Based Superalloys Containing Gamma-Gamma' Precipitates, vol. 57 (Cham: Springer International Publishing, 2015), pp. 67-96.

31. M. Ardeljan, R.J. McCabe, I.J. Beyerlein, and M. Knezevic, Comput. Method Appl. M 295, 396 (2015).

32. M. Ardeljan, M. Knezevic, T. Nizolek, I.J. Beyerlein, N.A. Mara, and T.M. Pollock, Int. J. Plasticity 74, 57 (2015).

33. B. Devincre, L. Kubin, and T. Hoc, Scripta Mater. 54, 741 (2006).

34. H. Moulinec and P. Suquet, Comput. Method Appl. M 157, 69 (1998).

35. P. Eisenlohr, M. Diehl, R.A. Lebensohn, and F. Roters, Int. J. Plasticity 46, 37 (2013).

36. P. Shanthraj, P. Eisenlohr, M. Diehl, and F. Roters, Int. J. Plasticity 66, 31 (2015).

37. M. Daamen, C. Haase, J. Dierdorf, D.A. Molodov, and G. Hirt, Mat. Sci. Eng. A, 627, 72 (2015).

38. D. Yan, C.C. Tasan, and D. Raabe, Acta Mater. 96, 399 (2015).

39. C.C. Tasan, J.P. M. Hoefnagels, M. Diehl, D. Yan, F. Roters, and D. Raabe, Int. J. Plasticity 63, 198 (2014).

40. C.C. Tasan, M. Diehl, D. Yan, C. Zambaldi, P. Shanthraj, F. Roters, and D. Raabe, Acta Mater. 81, 386 (2014).

41. D. Cereceda, M. Diehl, F. Roters, D. Raabe, J.M. Perlado, and J. Marian, Int. J. Plasticity 78, 242 (2016).

42. C. Reuber, P. Eisenlohr, F. Roters, and D. Raabe, Acta Mater. 71, 333 (2014).

43. J. Pospiech, K. Sztwiertnia, and F. Haessner, Textures Microstruct. 6, 201 (1986).

44. A. Ebrahimi and T. Hochrainer, MRS Adv. 1, 1791 (2016).

45. C. Kords, PhD thesis, RWTH Aachen, Berlin (2013).

46. P. Shanthraj, L. Sharma, B. Svendsen, F. Roters, and D. Raabe, Comput. Method Appl. M, 312, 167 (2016).

47. P. Shanthraj, B. Svendsen, L. Sharma, F. Roters, and D. Raabe, J. Mech. Phys. Solids, 99, 19 (2017). 